\title{
Ge Graphos

\section{PERCEPCIÓN Y ESPACIO URBANO: EL COMPORTAMIENTO DE LOS HABITANTES DEL BARRIO MARÍA AUXILIADORA DE NOVELDA (ALICANTE)}

\author{
$M^{a}$ Magdalena Villena Martínez \\ Estudiante de la Licenciatura de Geografía. Universidad de Alicante (España) \\ Correo electrónico: mmvm3@alu.ua.es
}

Recibido: 6 de marzo de 2012. Devuelto para revisión: 12 de junio de 2012.

Aceptado: 31 de julio de 2012

\section{RESUMEN}

Existen varios modos de estudiar la morfología y las características de una ciudad o espacio urbano: a través de cartografía oficial, de fotografía aérea, de datos estadísticos de tipo social o económico o a través de su historia. Este es el modo más difundido para el análisis y actuación de los expertos, donde el ser humano aparece como un espectador pasivo que vive en un espacio objetivo, sin sentimientos y experiencias vividas. Sin embargo, la ciudad también puede ser estudiada desde otra perspectiva donde convierte al ciudadano en su personaje principal, aquel que vive en la ciudad según su percepción. Con ello se pretende estudiar el espacio subjetivo, la dimensión vivida y percibida de sus habitantes que son los que realmente conocen el espacio donde viven.

Palabras clave: Percepción, comportamiento, espacio urbano, barrio María Auxiliadora, Novelda.

\section{URBAN SPACE AND PERCEPTION: THE INHABITANT'S BEHAVIOUR OF THE NEIGHBORHOOD MARÍA AUXILIADORA OF NOVELDA (ALICANTE)}

\begin{abstract}
There are several ways to study the morphology and characteristics of a city or urban space: through official mapping, aerial photography, social or economic statistics or throughout its history. This is the most widely used mode for analysis and performance of experts, where humans appears as a passive bystander who lives in an objective area, without feelings and experiences. However, the city can also be studied from a different perspective where the citizen becomes his main character, one who lives in the city
\end{abstract}


according to their perception. It is intended to study the subjective space, the dimension lived and perceived by its people that are who really know the area where they live.

Keywords: Perception, Behavior, Urban Space, María Auxiliadora Neighborhood, Novelda.

\section{PERCEPCIÓN E ESPAÇO URBANO: O COMPORTAMENTO DOS HABITANTES DO BAIRRO MARÍA AUXILIADORA DE NOVELDA (ALICANTE)}

\section{RESUMO}

Há várias maneiras para estudar a morfologia e as características de uma cidade ou espaço urbano: através de mapeamento oficial, fotografia aérea, estatísticas sociais ou económicas ou ao longo da sua história. Este é o modo mais utilizado para análise e desempenho de especialistas, onde os seres humanos aparece como um espectador passivo que vive em uma área objetiva, sem sentimentos e experiências. No entanto, a cidade também pode ser estudada numa perspectiva diferente, onde o cidadão torna-se seu personagem principal, aquele que vive na cidade de acordo com sua percepção. Destina-se a estudar o espaço subjetivo, a dimensão viveu e percebida que seus habitantes são aqueles que realmente conhecem a área onde eles vivem.

Palavras-chave: Percepção, comportamento, espaço urbano, bairro María Auxiliadora, Novelda.

\section{INTRODUCCIÓN}

En el planeamiento urbano de una ciudad, tradicionalmente se ha actuado sin tener consideración de los ciudadanos, los cuales tienen una serie de sentimientos y experiencias del lugar que habitan y son los que en última instancia van a desarrollar su vida en la ciudad. Únicamente se dejaba actuar al ciudadano en la fase final del proyecto y desarrollo técnico del plan general, además, se requería una formación para poder opinar adecuadamente sobre estos planes generales, con lo cual los que aprovechaban esta pequeña participación ciudadana terminaban siendo los propietarios y las empresas inmobiliarias. El resultado es el surgimiento de nuevos espacios en la ciudad creados por actores políticos o económicos. De esta manera, en la planificación tradicional, el papel del ciudadano es meramente pasivo, pues se limita a ser el sujeto de análisis de la realidad que ordena el planificador, a entender las consecuencias que tendrá el planeamiento en su vida cotidiana, y a aprobar las consecuencias de la ordenación territorial (Boira, 1996). Si el ciudadano fuese una figura activa en el planeamiento habrían muchas más ventajas, puesto que el técnico aprendería de los ciudadanos para elaborar su ordenación y los ciudadanos aprenderían a reflexionar sobre su medio.

Esta idea de incorporar en el planeamiento los análisis sobre el espacio subjetivo podría ser muy fructífera, pues se favorece la participación ciudadana y se facilitan datos al técnico o especialista que pueden ser de gran relevancia para hacer una planificación a medida de las personas, que a fin de cuentas debería ser el objetivo del planeamiento, es decir, conseguir el bienestar del ciudadano sin entrar en el juego del capitalismo. 
La aproximación al espacio subjetivo en Geografía se ha conseguido a partir de diversas fuentes como encuestas, entrevistas y el estudio de cartografía subjetiva de un determinado espacio. Asimismo, no es únicamente esta información la que debe tener consideración en un planeamiento y estudio de Geografía de la percepción, también se debe tener en cuenta la dinámica histórica, social, la situación económica y política y los elementos normativos de legalidad, puesto que son factores que influyen en la construcción de la realidad.

Así pues, si se adecuan estas ideas a diversos casos de ordenación territorial de ámbitos locales, se puede considerar que muchos han sido los fracasos en los planeamientos, y al ponerse en práctica lo decidido empiezan a producirse dificultades no previstas, y aquello que iba a ser beneficioso para los ciudadanos, empieza por convertirse en motivo de conflicto. Es por ello que el objetivo de este análisis y diagnóstico completo se centra en estudiar cómo ha repercutido el planeamiento del barrio María Auxiliadora de Novelda (Alicante) (Figuras 1, 2 y 3) sobre la percepción los habitantes de Novelda, teniendo en consideración aspectos de tipo económico, social y cultural que han determinado una singular imagen de este barrio respecto a otros barrios de Novelda.

Este análisis del barrio María Auxiliadora se consiguió llevar a cabo con la recogida de encuestas, entrevistas y mapas mentales elaborados por los ciudadanos noveldenses de distintos barrios de procedencia a fin de explorar y clasificar los sentimientos de frustración y/o esperanza en su "barrio vivido" (De la Vega, 1944).

La situación del municipio de Novelda respecto a su territorio está evidentemente referida a la dependencia y aprovechamiento tradicional del medio natural. La organización de la población se relaciona con la estructura productiva y los factores tecnológicos, y es preciso entender los procesos territoriales dentro del contexto social, funcional y ambiental de la localidad. En particular, el barrio de María Auxiliadora, antiguamente llamado barrio de las Horcas, empezó a surgir a partir del camino que unía San Roque con Novelda y con Aspe (Alicante), antiguo camino carretero del siglo XVII que daba la alternancia al viejo camino de Elche (Campet). Ya en los años 50 del siglo XX empieza a desarrollarse poco a poco el barrio, estrenando además actuaciones del Ministerio de la Vivienda y anchos de calle generosos, donde se adivinaba la expansión que se avecinaba en años posteriores, pues en los años 70 del siglo XX se produce una inmigración notable que traspasa los límites de la ciudad, creándose como tal el barrio María Auxiliadora y abriendo viales (Avda. de la Constitución) y calles que lo conectan con la ciudad existente. Durante los años 70 del siglo XX se prosigue la edificación de este nuevo barrio de expansión hasta la actualidad (Sala, 2009).

El método seguido en el estudio ha consistido en una labor de encuesta a cuarenta y cuatro personas, efectuadas bajo el fin de que se pudieran obtener puntos de vista distintos por un variado colectivo de edad, sexo y diferente nivel cultural. Además, se llevó a cabo una elaboración de la imagen mental de cada uno de los encuestados. 
Figura 1. Situación de Novelda respecto a España

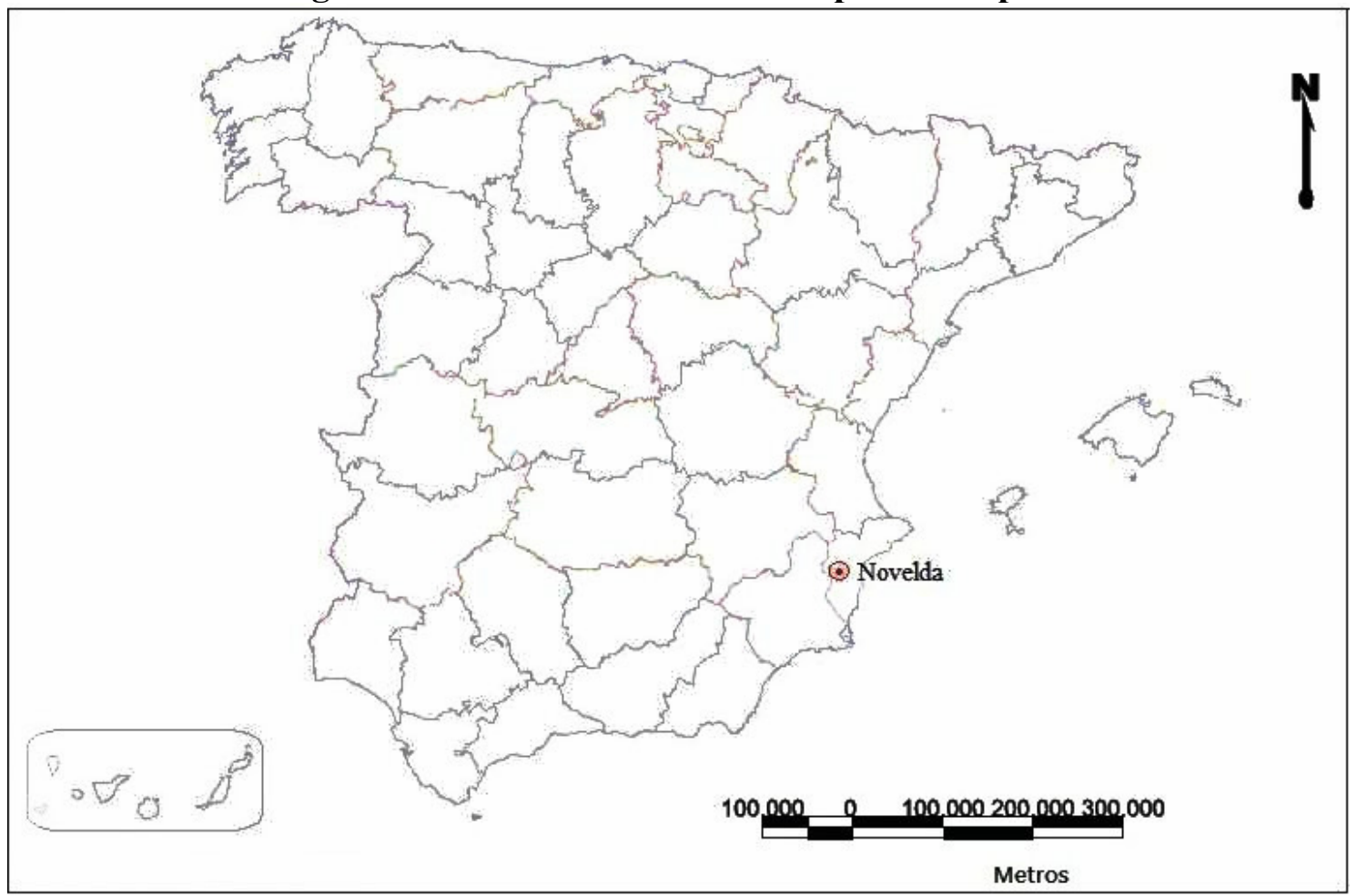

Fuente: Elaboración propia.

Figura 2. Situación de

Novelda respecto a

la Comunidad

Valenciana

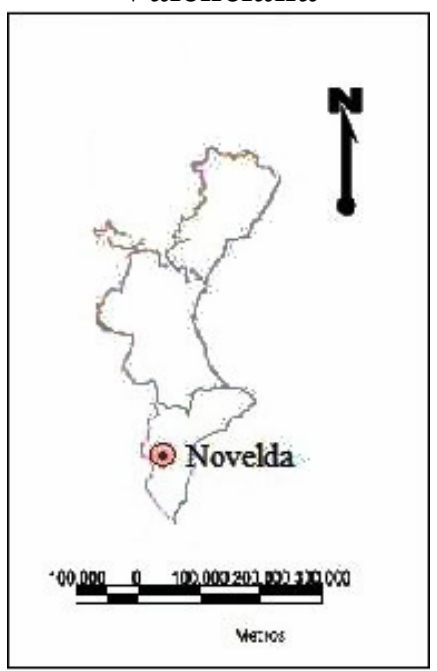

Fuente: Elaboración propia. 


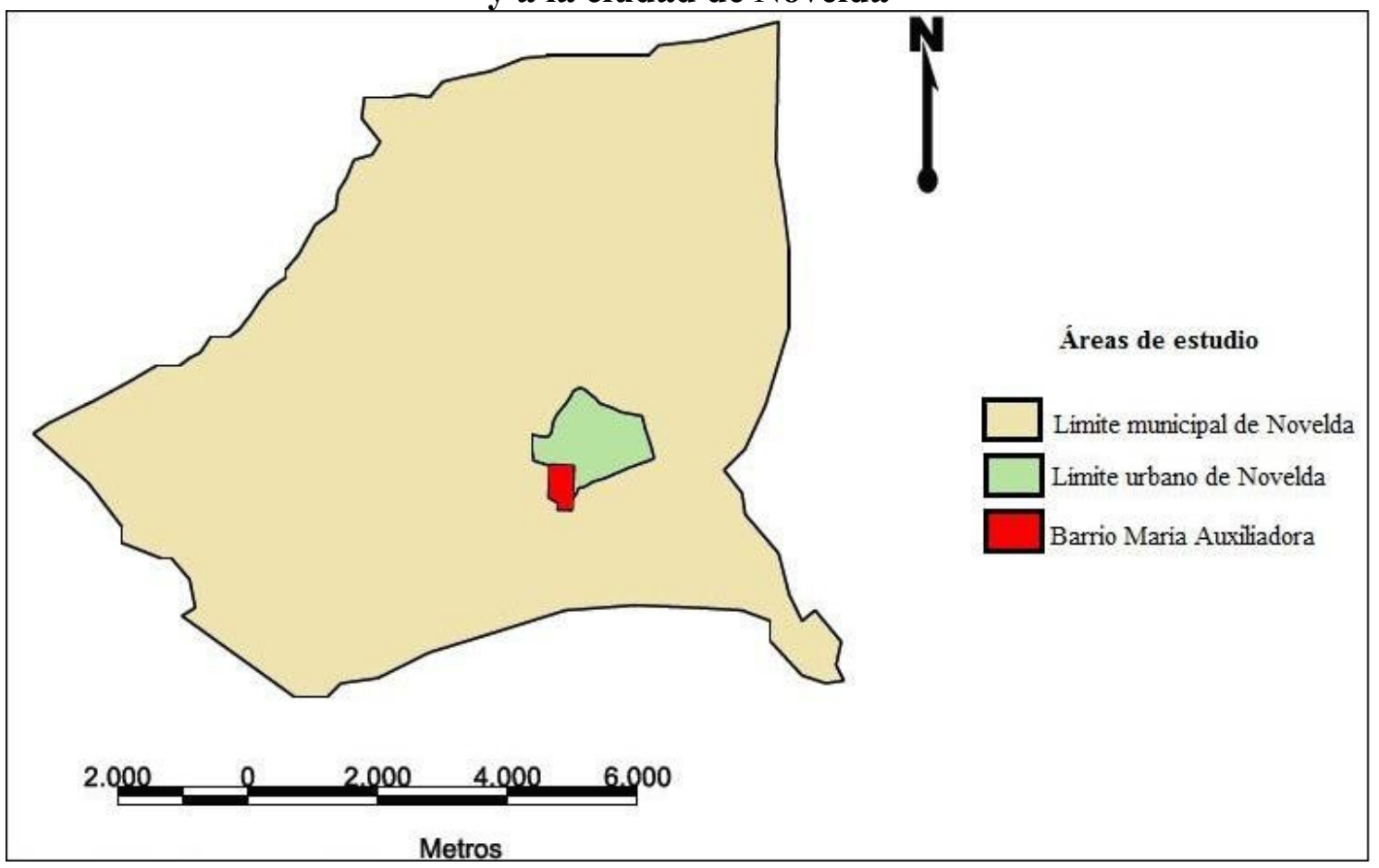

Fuente: Elaboración propia.

\section{MARCO TEÓRICO}

La Geografía de la percepción, a partir de los años 60 del siglo XX, se adentra en el mundo subjetivo de las personas y en las imágenes mentales que los individuos tienen sobre el espacio que viven, iniciando una etapa de "revolución del comportamiento". El "behaviorismo" o conductismo, escuela psicológica de Estados Unidos, le facilita a la Geografía el estudio personal de los seres humanos.

Esta vertiente de la Geografía hunde sus raíces en trabajos de K. E. Boulding (1956) ante la protesta de los esquemas de modelos económicos en la Geografía cuantitativa, en donde aparece el hombre y todas sus acciones racionalmente distribuidas en el espacio siguiendo unos criterios económicos (Homo economicus). Ahora se trata de ir más allá, de tratar de entender al individuo, de interpretar su propia realidad y de intervenir según sus necesidades a fin de mejorar su calidad de vida (Millán, 2004).

Según M. Santos (1990), “este enfoque se basa en que cada individuo tiene una manera concreta de conocer el espacio, así como de evaluarlo [...]. Este espacio social está definido por los lugares que le son familiares y por las parcelas de territorio que debe recorrer entre esos diferentes lugares". Además añade que "esta tendencia representa, en cierta forma, una ruptura con el economicismo y una forma de restitución de los valores individuales".

Con lo cual, el individuo genera un mapa del espacio propio, que como afirma C. de Castro (1997) "es una realidad activa en nuestro comportamiento; orienta nuestros pasos en el desplazamiento y ahuyenta el riesgo de perdernos en la jungla urbana". 
Cada individuo o grupo social tiene una percepción sesgada de la realidad objetiva, pues esta realidad se ve condicionada por sus valores culturales, sus experiencias, sus aspiraciones, etc., es decir, una serie de características que conducen al ser humano a crear su propio universo que se organiza concéntricamente sobre él y que tiene un espacio inmediato que es el medio donde habita, espacio con una información personal y directa.

Varios estudios de Geografía de la percepción han ofrecido sustanciosos resultados, como por ejemplo los elaborados por J. Bosque, C. de Castro, M. A. Díaz, y F. J. Escobar (1992), que llegaron a la conclusión de que "los lugares geográficos no solamente están fuera de nosotros con una existencia física que les pertenece, sino también están dentro de nuestras mentes. Explorar la existencia mental de los lugares geográficos con todas las características que los dibujan es un objetivo propio de la Geografía de la percepción”.

Con la obra de K. Lynch, La imagen de la ciudad (1960), se pudo conseguir un marco teórico a seguir en los trabajos aplicados de muchos geógrafos de la percepción. Su metodología era conseguir una serie de imágenes de los elementos de la ciudad medidos a partir de sendas, nodos, mojones, distritos y bordes, que finalmente servían para conocer las relaciones sociales y emotivas del ciudadano con el medio que habita.

La Geografía de la percepción emplea como instrumento metodológico los mapas mentales, es decir, croquis dibujados espontáneamente por el individuo sobre un determinado espacio, cargados de subjetividad. Estos mapas incluyen su experiencia sensorial actual y experiencias pasadas que conectan lugares ya habitados anteriormente por él con el presente, obteniendo con ello una utilidad práctica (orientación) y algunas utilidades de orden psicológico, pudiendo desarrollar en el individuo una seguridad afectiva dentro de la sociedad en que habita (Vara, 2008).

De esta manera, los mapas mentales son fundamentales porque ofrecen de cada individuo su visión particular del medio, características que difieren según la edad, hombre o mujer, destreza para dibujar, cultura y experiencia y conocimiento del medio. El resultado es que estas imágenes o realidades percibidas se interponen entre el ser humano, el mundo real y su conducta, y pueden ser muy ricos a la hora de entender ciertos problemas que un técnico o arquitecto urbanista no entienden. No obstante, el objetivo no es fundamentar los planes de urbanización en estos análisis de Geografía de la percepción, sino que sirvan como complemento a su elaboración a fin de conseguir que en el futuro vivamos en unas ciudades más humanas.

\section{APLICABILIDAD DEL MÉTODO GEOGRÁFICO EN LA PERCEPCIÓN Y PRÁCTICA DEL DESARROLLO}

Los ciudadanos no se comportan en el espacio urbano con racionalidad, sino atendiendo a unas imágenes distorsionadas y fragmentarias de la ciudad. Todas las personas poseen una imagen determinada del espacio urbano sobre la cual actúan y toman decisiones, factor éste que predomina sobre la realidad objetiva del espacio. Éste vendría a ser el problema entre los ciudadanos y los planificadores, es decir, la no coincidencia para ambos de un mismo espacio. Así pues, con el objeto de vencer esta problemática se hace fundamental la participación activa del ciudadano empleando encuestas sobre 
percepción y comportamiento urbano, que sería el objeto de estudio de la Geografía de la percepción. El método científico en el análisis de la percepción parte del estudio del medio objetivo y posteriormente de las imágenes de los ciudadanos, para que finalmente se puedan comparar y detectar las imperfecciones del conocimiento sobre ese espacio, así como encontrar las claves para entender el sentido de lugar de sus habitantes.

El objetivo de este estudio es analizar las perspectivas y opiniones que los noveldenses tienen del barrio María Auxiliadora con el fin de conseguir conclusiones que destaquen los puntos fuertes y los puntos débiles que el barrio en cuestión presenta y el distinto modo de percibirlo según el ciudadano y sus características.

La elaboración de este trabajo se relaciona con la apreciación que tiene por parte de los habitantes del barrio como una zona alejada del núcleo urbano de Novelda, sin un desarrollo amplio comercial, industrial y de servicios y poblado por unos habitantes de avanzada edad, hecho este último que podría justificar principalmente las carencias que se señalaban anteriormente, puesto que en última instancia es la causa estructural que genera estas deficiencias por la falta de vitalidad y nuevos proyectos del barrio.

Este tipo de estudios son muy importantes para entender el espacio de la gente que vive y trabaja realmente en él, esto es, extraer el aspecto más humano del territorio lejos de concepciones puramente materialistas del espacio objetivo, el cual no conformaría absolutamente nada sin el aspecto humano, que en esencia este ha dado la génesis a estos espacios, convirtiéndolos en "espacios vividos, simbólicos y afectivos", como afirman J. Boira, P. Reques y X. Souto (1994) en esta cita: "El espacio no puede ser interpretado como un campo neutro donde funciones y procesos se desarrollan, sino como un escenario vivido que se quiere, se odia, se respeta u olvida según la percepción del ciudadano".

Además, sobre el espacio se crean una serie de conductas y sentimientos según experiencias sensoriales, memorias, idealizaciones, etc. y se percibe de distinto modo según clase social, edad, sexo, puesto laboral...Es en este aspecto de donde Yi-Fu Tuan (1974) distingue entre topofobia como un espacio considerado desagradable, y topofilia como un espacio agradable, y también topolatría si se despierta un sentimiento reverencial hacia el espacio. Con lo cual, se puede decir que el ser humano no se comporta en el espacio urbano racionalmente, sino que lo hace en función de la distorsionada y fragmentaria imagen que posee de un determinado espacio, es decir, de las características reales del espacio y de las valoraciones y preferencias personales.

Con este análisis del barrio María Auxiliadora se hace posible conocer la capacidad que tiene el barrio de provocar imágenes, que a fin de cuentas es de lo que depende su eficiencia, pues la "legibilidad" (Lynch, 2010) del barrio para los individuos es indispensable para generar un recorrido a partir de imágenes distintivas en secuencia, y también nos informa del grado de participación del ciudadano con el barrio y con sus habitantes.

Asimismo, con este estudio que revela las distintas imágenes del barrio que elaboran sus usuarios, se vienen a señalar los problemas más importantes que presenta. Este aspecto sería interesante a la hora de colaborar en un proceso de planificación urbanística ya que desempeña un papel concreto en la estructuración del espacio. También abre nuevas posibilidades de análisis geográfico, como el planeamiento y diseño ambiental, patrones 
de comportamiento individual, significado simbólico del territorio...Y en cuanto a los ciudadanos, despierta un sentimiento crítico respecto a la manipulación sistemática que del mundo real se hace a través de la distorsionada, fragmentaria e interesada imagen que del mismo se ofrece.

Para iniciar el estudio sobre el barrio, se llevaron a cabo unas entrevistas personales, dejando fluir las frases e ideas y estableciendo una comunicación abierta y sensible con el entrevistado, con preguntas amplias a distintos colectivos, edades, sexos..., sumando finalmente la elaboración de un mapa mental sobre aquellas áreas que más frecuentaban o conocían del barrio. Para la entrevista se siguieron los tres enfoques propuestos por Downs (Teoría de la elección racional): el enfoque estructural, que consiste en averiguar cómo se percibe la información del lugar; el enfoque valorativo, que trata en conocer cómo se valora el espacio según decisiones específicas; y el enfoque preferencial, que es un análisis de preferencia con otros lugares.

En total fueron cuarenta y cuatro los entrevistados, y aportaron información muy variada y bastante significativa de sus distintos "archivos mentales" del barrio María Auxiliadora, con múltiples imágenes y distintos esquemas cognitivos del mismo variando según intereses, comportamientos personales y características de la persona. Así pues, la percepción es algo muy complejo, porque no sólo intervienen los sentidos o la "percepción pasiva", (Gibson, 1996), sino que también aparecen la memoria, la personalidad, la cultura, es decir, la "percepción activa" (Gibson, 1996). En este aspecto profundiza M. Millán (2004), pues "resulta habitual aceptar que cada individuo, cada grupo social, posee una percepción sesgada de la realidad objetiva. Pero es así porque está condicionada por sus valores culturales, sus experiencias y sus aspiraciones, unos aspectos que conducen al hombre a un universo propio que se organiza concéntricamente en torno de sí mismo y en este contexto su esfera más inmediata es el medio de su actuación habitual, del que posee una información personal y directa".

Con el objeto de conocer las relaciones sociales y emotivas que los individuos establecen con el medio, K. Lynch (2010) enumera los elementos que permiten estructurar el espacio y darle legibilidad, dividiendo el espacio en ejes estructurales (sendas: calles, senderos, líneas de tránsito, canales o vías férreas), en relaciones de ejes (nodos: puntos estratégicos, confluencias; barrios o distritos: secciones de la ciudad; y barreras: límites) y en referencias y puntos marcadores (hitos: puntos de referencia). Y sobre estos elementos se ha fundamentado el análisis espacial, dando como resultado la figura 4, que sintetiza todos los aportados por los entrevistados: 


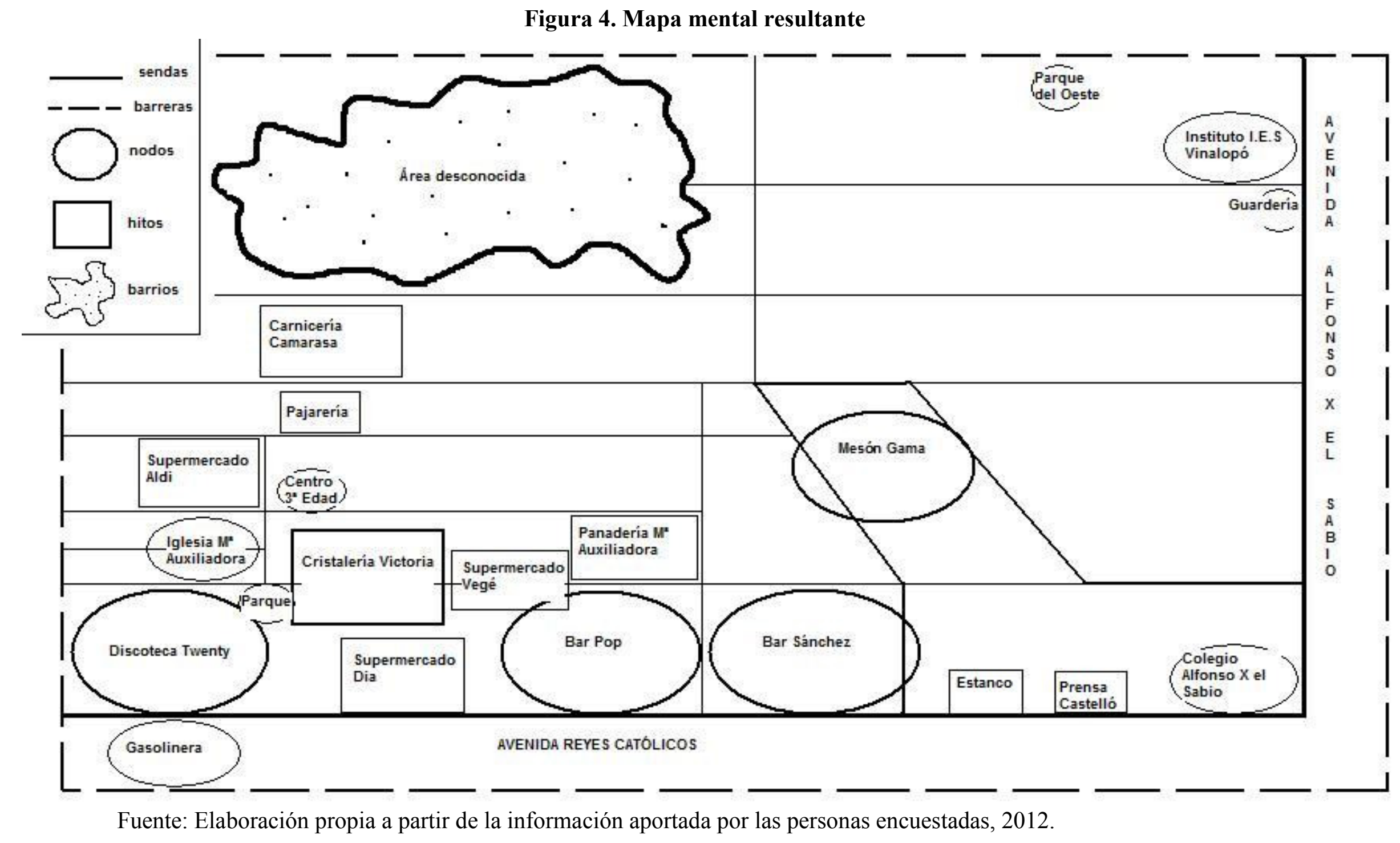


La visión personal de cada entrevistado para realizar los mapas ha tenido mucha relación sobre todo con su edad, sexo, nivel de formación y algunos aspectos personales. El ser humano interacciona con los individuos y su entorno a través de actividades cotidianas, inherentes a nuestra condición humana y a las actividades que realizamos en la organización social (trabajar, educarse, habitar una vivienda, abastecerse de bienes y servicios, emplear el tiempo libre, mantener relaciones sociales...), actos que se realizan en un lugar determinado, es decir, en los lugares funcionales (Díaz, 1997) (residencia, lugar de trabajo, colegios...) que aparecen dispersos en el espacio y que obligan a un desplazamiento, con lo cual, nuestra vida cotidiana se estructura en un conjunto de ritmos y rutinas estructurados por la localización en el espacio y en el tiempo de los lugares a los que asistimos.

Así pues, estos mapas mentales son una organización viva de la información espacial, y este conocimiento que tienen los entrevistados del barrio les capacita para la solución de problemas espaciales del día a día con un roce cotidiano que va aportando nuevos conocimientos geográficos (De Castro, 1997).

Estos mapas son, en esencia, datos en forma bruta conectados y aportados de forma sensorial, de los cuales han ido surgiendo los mapas mentales que nutrirán la capacidad de comunicación o de toma de decisiones a partir de un proceso consistente en pasar de la sensación multisensorial a la percepción del entorno urbano. Sin embargo, hay otras influencias que actúan sobre este resultado, como el significado social de la zona, su función, etc.

Asimismo, cabe destacar la importancia de los desplazamientos (De Castro, 1997), ya que trasladarse supone una fuente de información permanente para reconstruir y actualizar el entorno. No obstante, todo movimiento por el espacio implica previamente un desplazamiento mental diseñado de información selectiva que se ha percibido (inconscientemente) según la experiencia y la conducta. Con todo, podemos decir que la vida urbana reclama un mapa mental que ayude a navegar espacialmente por el territorio.

En estos mapas cognitivos obtenidos se encuentra una visión muy alejada de la racionalidad geométrica que nos proporcionan los planos o mapas convencionales, puesto que lo único que sirve para movernos geométricamente por el espacio son las abstracciones geométricas, esto es, el sistema de orientación humana con referencias espaciales que se encuentran permanentemente en las palabras (recto, derecha, izquierda, norte, sur...) que constituyen el significado del medio. Así pues, el mapa mental tiene entidad propia y no debe confundirse con el aprendizaje de una geometría (De Castro, 2004).

Del mapa síntesis obtenido de todos los mapas dibujados, podemos afirmar que ha guardado un pequeño punto de fidelidad en cuanto al mapa geométrico del barrio. Un aspecto fundamental que ha incidido a distinguir plenamente la percepción del barrio, ha sido la forma de desplazarse en él, ya que las personas que han sido entrevistadas y se movilizan en el barrio con automóvil, han captado pocos elementos del mismo, más que nada grandes vías y calles que enlazan con algún punto clave, puesto que la legibilidad visual se reduce, y el código circulatorio impone severas restricciones a una experiencia de percepción plena. Y por el contrario, el que lo transita andando realiza 
unas representaciones menos distorsionadas, incluyendo un mayor número de detalles y elementos.

Además, se puede decir que los mapas cognitivos están regidos por los ciclos de vida porque describen determinados entornos según la edad: residencial, escolar, comercial, etc. A los entrevistados de entre 16 y 20 años destacan más las áreas escolares y los parques; a los de edades 20-28 áreas de ocio (discoteca); y a los de más de 30 años áreas comerciales y restaurantes. Este hecho está relacionado con los usos que hacen del barrio, siendo los más comunes en el estudio, por cuestiones familiares y relacionados con restaurantes y bares.

Asimismo, la edad también influye a la hora de añadir elementos al mapa, puesto que los individuos más jóvenes han aportado una mezcla de construcciones antiguas y modernas (por ejemplo, la discoteca y el supermercado Vegé), y los individuos más mayores, en general, construcciones antiguas e incluso desaparecidas como el caso del centro de la tercera edad inexistente hoy en día, ya que la aprehensión de nuevos elementos del barrio les es más lenta.

También cabe considerar que a medida que el sujeto se aleja de su lugar de residencia respecto al barrio María Auxiliadora, los detalles van decreciendo. Se han obtenido mapas con información muy rica de varios habitantes de este barrio, y al contrario, información muy pobre de aquellos ciudadanos de Novelda que viven en barrios más alejados del estudiado, influyendo también en las concepciones de dimensiones y distancias, que se convierten en aproximaciones más distorsionadas cuanto más lejos residan del barrio en cuestión.

Asimismo, los entrevistados han comparado el barrio con otros barrios o estereotipos de barrios, idealizando barrios más culturales, con zonas peatonales, con una elevada calidad estética, zonas verdes, etc., hecho que ha repercutido a la hora de valorar el barrio negativamente. Además, el grado de relación con el barrio es menor si el individuo reside lejos del mismo, factor que nos delata que el sujeto está poco involucrado con el barrio y su sociedad.

Un factor que ha llamado la atención, es que los entrevistados no sabían delimitar bien el barrio, incluyendo en sus mapas cognitivos elementos que no pertenecen al barrio María Auxiliadora, como el Parque del Oeste o el Supermercado Dia, que seguramente sean percibidos como un borde.

A partir de varias cuestiones realizadas a los entrevistados para obtener mayor información, se pudieron obtener otros aspectos más personales que influyen a la hora de organizar el territorio. Todos los entrevistados afirmaron que se trataba de un barrio de gran extensión, alejado del vivir cotidiano y del centro del pueblo, -incluso un entrevistado añadió que antiguamente se decía "ir al pueblo" cuando iban a desplazarse al centro de Novelda-, muy tranquilo, con un declive demográfico marcado por sus habitantes de avanzada edad, y con una falta de dinamismo económico por la ausencia casi plena de comercios, servicios e industria, como decía una entrevistada: "es un barrio residencial, pobre, obrero y periférico...es una zona de gran marginalidad, sin servicios, de uniformidad manifiesta, de carácter cerrado y formaciones rígidas". 
Muchos aspectos fueron considerados positivos (fortalezas, oportunidades), como la tranquilidad, la relación positiva entre los vecinos y la buena estructuración en cuanto a sus calles, pero también se destacaron aspectos negativos (debilidades, amenazas), como la ausencia de movimiento y sociabilidad, la lejanía respecto al centro de Novelda donde están los servicios cotidianos, el chismorreo entre los vecinos por la vida de calle, la degradación de algunos edificios, la falta de intimidad entre casas por estar muy unidas, la falta de instalaciones deportivas, la carencia de servicios para la atención de la población senil, la ausencia de zonas verdes amplias y la contaminación acústica los fines de semana por los bares y la discoteca, aspecto este último muy enfatizado por los habitantes del barrio.

Cuadro 1. Resultados de las deficiencias del barrio María Auxiliadora

\begin{tabular}{|c|c|c|}
\hline CARENCIAS & NÚMERO DE RESPUESTAS & \% \\
\hline Comercio & 38 & $20{ }^{\prime} 2$ \\
\hline Centro Cultural & 37 & $19^{\prime} 6$ \\
\hline Polideportivo & 31 & $16^{\prime} 4$ \\
\hline Ocio & 24 & $12^{\prime} 7$ \\
\hline Espacios verdes & 18 & $9^{\prime} 5$ \\
\hline Urbanización & 17 & $9^{\prime} 0$ \\
\hline Otras & 13 & $66^{\prime} 0$ \\
\hline Nada & 10 & $5 ' 3$ \\
\hline
\end{tabular}

Fuente: Elaboración propia a partir de los datos aportados por los encuestados, 2012.

En general, hay sentimientos y prejuicios desfavorables sobre el barrio, alegando que tiene muchas carencias y necesidades. Asimismo, las propias características del barrio favorecen a que la situación sea peor, puesto que hay determinados aspectos funcionales que dificultan los contactos humanos, como por ejemplo la ausencia de puntos de diversión (recreativos, parques...), de instalaciones deportivas y de bibliotecas. Con lo cual el resultado es un barrio muy tranquilo, como todos los entrevistados destacaron, pero muy aburrido y sin perspectivas dinamizadoras para el futuro. Además, la posición respecto al centro de la ciudad y otros barrios, hace echar en falta líneas de autobuses que minimicen y acerquen ese espacio, aspecto este que da una sensación de lejanía y marginación a sus habitantes.

En definitiva, los resultados vierten que se trata de un barrio de convivencia por su vecindad y sus fiestas, valoradas positivamente por los noveldenses, un barrio con poco contacto por la existencia escasa de bares y restaurantes, un barrio amplio y bien estructurado y un barrio agradable y residencial, pero que cuenta con unas deficiencias que lo convierten en un barrio poco atractivo para vivir y hacer vida social. El estudio llevó a pensar que los ciudadanos de Novelda viven una especie de "toponegligencia" (Tuan, 1974), por la falta de arraigo y de sentido de pertenencia respecto al barrio, convirtiéndolo en un espacio lejano, ajeno e impersonal.

Esto nos lleva a la conclusión de que se necesita poner en marcha un programa de reestructuración del barrio, aspecto que enfatizaron todos los entrevistados, consistente fundamentalmente en un rejuvenecimiento de sus pobladores. Este punto podría conseguirse con la apertura de nuevos comercios que atraigan familias para residir cerca de su lugar de trabajo, y a partir de ahí crear una serie de equipamientos para estas 
familias, como podría ser centros de ocio y culturales, parques que sirvan como reunión social, bibliotecas, espacios deportivos, imponer un nuevo modelo de edificaciones que permitan un desarrollo vertical y rehabilitar las casas más degradadas para aportar un aspecto vivo y agradable estéticamente al barrio, además, intentar salvar ese distanciamiento del núcleo urbano favoreciendo el transporte público. Y en cuanto a la puntual contaminación acústica, adoptar medidas para evitarlo, como cerrar los espacios exteriores de los bares o crear patios insonorizados, así como tener un mayor control sobre la hora de cierre de estos locales.

No obstante, para este desarrollo y nuevas propuestas a fin de conseguir que el barrio María Auxiliadora se revitalice y no se aboque a una progresiva decadencia, es necesaria una actitud positiva y emprendedora de los efectivos locales que son los que tienen la capacidad de decisión con relación al desarrollo del territorio (Millán, 2004) para acometer una reestructuración profunda e incentivar a los más jóvenes para que se instalen en este barrio de Novelda que aparece muy difuminado y alejado para sus habitantes.

\section{CONCLUSIÓN}

Los hábitos de comportamiento se ven determinados por el planeamiento que marca itinerarios y marcas funcionales. Es por ello que la Geografía de la percepción se acerca a conocer las carencias y desviaciones del planeamiento, a la vez que intenta acercar y hacer participativo al ciudadano en la tarea de elaboración de un plan general del espacio que habita.

Los mapas mentales obtenidos han puesto de manifiesto que el ciudadano conoce plenamente las deficiencias y carencias que presenta el barrio María Auxiliadora y que podrían servir de gran utilidad a la hora de ordenar este territorio a fin de revitalizarlo y evitar su abandono y degradación, pues hay un riesgo muy elevado de que esto pueda tener lugar, ya que los principales habitantes del barrio son población senil.

La falta de atractivo del barrio queda afirmada, pues habitantes de otros barrios de Novelda tenían un conocimiento sesgado de la realidad del barrio. Además, hay un notable desequilibrio rotacional entre otros barrios y este que dejaron patente muchos de los encuestados.

Si a todas estas circunstancias añadimos su lejanía respecto al centro, y la presencia de un entramado callejero interno alejado del resto de la ciudad apoyado solo sobre dos ejes viales, el resultado es un barrio marginal, sin vitalidad y ausente de dinamismo social y económico.

De esa manera, en los esquemas cognitivos que marcan las pautas del comportamiento ciudadano se observan grandes vacíos, lagunas de conocimiento que dificultan la aprehensión del entramado urbano del barrio.

En definitiva, es necesario poner en marcha un estudio que plantee soluciones coherentes y propuestas urbanas que ayuden al bienestar del ciudadano. Se confía que las técnicas propias de Geografía de la percepción constituyen una herramienta muy fructífera para comprender mejor a la ciudad y a sus habitantes a fin de conseguir un 
diseño conceptual de la ciudad y una práctica enriquecedora entre la Administración y los administrados, es decir, entre el planificador y el ciudadano, como apoya A. Bailly (1989), quien destaca la necesidad de apostar por las aplicaciones destinadas a una ordenación del territorio más humana, ya que los seres humanos que habitan el territorio, por uno u otros motivos, se encuentran en una coyuntura poco favorable.

\section{BIBLIOGRAFÍA}

ANDRÉS, M. A. El barrio de Benalúa en Alicante: estudio de Geografía urbana. Alicante: Caja de Ahorros Provincial de Alicante, 1998.

BAILLY, A. La perception de l'espace urbain. Paris: centre de recherche d'urbanisme, 1977.

BAILLY, A. Lo imaginario, espacial y la Geografía. En defensa de la Geografía de las representaciones. Anales de Geografía de la Universidad Complutense, n 9, 1989, pp. 11-19.

BOIRA, J., REQUES, P., SOUTO, X. Espacio subjetivo y Geografia: orientación teórica y praxis didáctica. Valencia: Nau Llibres, 1994.

BOSQUE, J., DE CASTRO, C., DÍAZ, M.A., ESCOBAR, F. J. Prácticas de Geografía de la percepción y de la actividad cotidiana. Barcelona: Oikos-Tau, 1992.

BUZAN, T. El libro de los mapas mentales. Barcelona: Urano, 1996.

DE CASTRO, C. La Geografía en la vida cotidiana: de los mapas cognitivos al prejuicio regional. Barcelona: Ediciones del Serbal, 1997.

DE CASTRO, C. Mapas mentales. Pamplona: Universidad Pública de Navarra, 2004.

LYNCH, K. La imagen de la ciudad. Barcelona: editorial Gustavo Gili, 2010.

MILLÁN, M. La Geografía de la percepción: una metodología de análisis para el desarrollo rural. Papeles de Geografía, nº 40, 2004, pp. 133-149.

RAMOS, A., PONCE, G., DÁVILA, J. M. (Coord.). II Jornadas de Geografia Urbana. Murcia: Universidad de Alicante, 1996.

SALA, R. Quaderns de la Mola: 30 anys de Democràcia a Novelda (1979-2009). Novelda: CIEN, 2009.

SANTOS, M. Por una Geografia nueva. Madrid: Espasa Calpe, 1990.

TUAN, Y. F. Topofilia: un estudio de las percepciones, actitudes y valores sobre el entorno. Barcelona: Melusina, 1974.

VARA, J. L. Cinco décadas de Geografía de la Percepción. Ería, n 77,2008 , pp.371384. 


\section{RECURSOS ELECTRÓNICOS}

$<$ http://www.geobaires.geoamerica.org/textos/roze chicago.html $>$ [Consulta: 4 enero 2012)

$<$ http://132.248.35.1/cultura/2003/ponencias-2/Wpon5.html $>$ [Consulta: 4 enero 2012)

(c) Copyright Ma Magdalena Villena Martínez, 2012.

(c) Copyright GeoGraphos. Revista Digital para Estudiantes de Geografia y Ciencias Sociales, 2012. 